\section{Primate profiles}

\section{R.D. Martin}

Primates of the World: Distribution,

Abundance, and Conservation.

By Jaclyn $\mathbf{H}$. Wolfheim.

University of Washington Press/

Harwood Academic: 1984. Pp. 832.

\$46 (US), $\$ 72$ (Britain and Europe).

WiTH the exception of the Red Data Book (Mammalia), a publication only partly devoted to primates and limited to the most basic information, there is no standard reference work regarding the conservation status of prima. 2 s. In Primates of the World, Jaclyn Wolfheim has set out to remedy that situation.

In the book, a vast amount of literature is covered (there are over 1,000 references) and the available information is brought together into a well-designed framework. The text deals with the primates on a species-by-species basis and for each species provides information on geographical distribution, population parameters, habitat conditions, factors reported to affect wild populations, and conservation action under way. The profile for each species is accompanied by a distribution map and (where data exist) by a table summarizing population parameters. The distribution maps, which generally indicate maximum possible areas of present occurrence, have been carefully prepared and provide reasonably accurate guidelines. In this and other respects, Wolfheim made a concerted effort to ensure accuracy by incorporating results from questionnaires circulated to 226 field workers.

The reference value of Primates of the World has been enhanced in a number of ways. Most particularly, it is commendable that the author took pains to use a broadly comprehensible and acceptable scheme of classification; only a conservative scheme, such as the one adopted here, is likely to be readily understandable to the many different groups of people who are likely to use the book. Secondly, the species profiles are followed by a 20-page discussion that identifies a number of general principles, and by seven summary tables (one as an appendix) listing quantitative information across species. Two especially useful tables are one listing "major determinants of population status" (including an estimate of the maximal geographical range for each species in square kilometres) and another relating scores for these determinants to overall conservation status. The quantitative data provided have not been analysed by Wolfheim herself, but should provide at least a provisional basis for mathematical modelling in primate conservation programmes.

However the book does have its limitations. Perhaps unavoidably, it is already quite out of date, coverage of the literature effectively ending at 1978 (all the references for 1979 and 1980 seem to stem from two edited works). Further, there are no descriptions or illustrations of individual species; hence anyone not already familiar with living primates will need a back-up reference source. It is also a pity that Table 190 gives body weights for only just over half of the primate species, and even then cities maximal body weights largely derived from captive animals. Finally, some of the information (for instance on primate importation and on the associated

legislation) is specifically relevant to the United States only, rather than being genuinely international.

But, overall, Jaclyn Wolfheim has done an excellent job. With one-third of the present total of about 150 primate species already listed as endangered, rare or threatened by the International Union for the Conservation of Nature, a source-book such as this was urgently needed.

R.D. Martin is Professor of Physical Anthropology at University College London.

\section{A view of life}

\section{A.J. Cain}

\section{A Synoptic Classification of Living}

Organisms.

Edited by R.S.K. Barnes.

Blackwell Scientific/ Sinauer: 1984. Pp. 273. Pbk f7.50, \$11.50.

DR BARNES has organized a most useful little book, giving a quick view of the diversity of living things, and designed as "the sort of dictionary/mini-encyclopaedia of organismal classification and diversity that all professional, amateur and student biologists could have on their desks". As he remarks, "student biologists are taught less and less of the diversity of life'". It is hoped that this book will do something to remedy the defect; yet since it goes only to orders, and there is a single illustration for each phylum, it can do so mainly by sending its readers to more widely-illustrated or detailed texts. As such, it will be valuable.

The classification is a consensus, and avoids some of the wild splitting of recent texts. Viruses are excluded as not coming within the definition of living things, and only groups with some living representatives are admitted - for example, the Merostomata are in, because of the horseshoe crabs, but the trilobites are not; the Chelonia, Rhynchocephalia, Squamata and Crocodilia are in but the various dinosaurs, ichthyosaurs and plesiosaurs are not. Perhaps a later edition can include them.

The Introduction is so brief as to be misleading in one particular: "Taxonomic categories of whatever level are arbitrary, man-made distinctions imposed on a continuum of natural variation" is a dangerous half-truth. It is not open to anyone to include human beings, Drosophila and snails in a single group. As G.G. Simpson has stressed, taxonomic categories are arbitrary by exclusion, not arbitrary by inclusion. And there isn't a continuum indeed the definition of phylum status provided in the book is based on gaps.

No one will be entirely satisfied by the classification given here, but the five collaborators have done a good job. May I assist by pointing out that the Marsupialia have been divided into several orders for some time now?

A.J. Cain is Derby Professor of Zoology at the University of Liverpool.

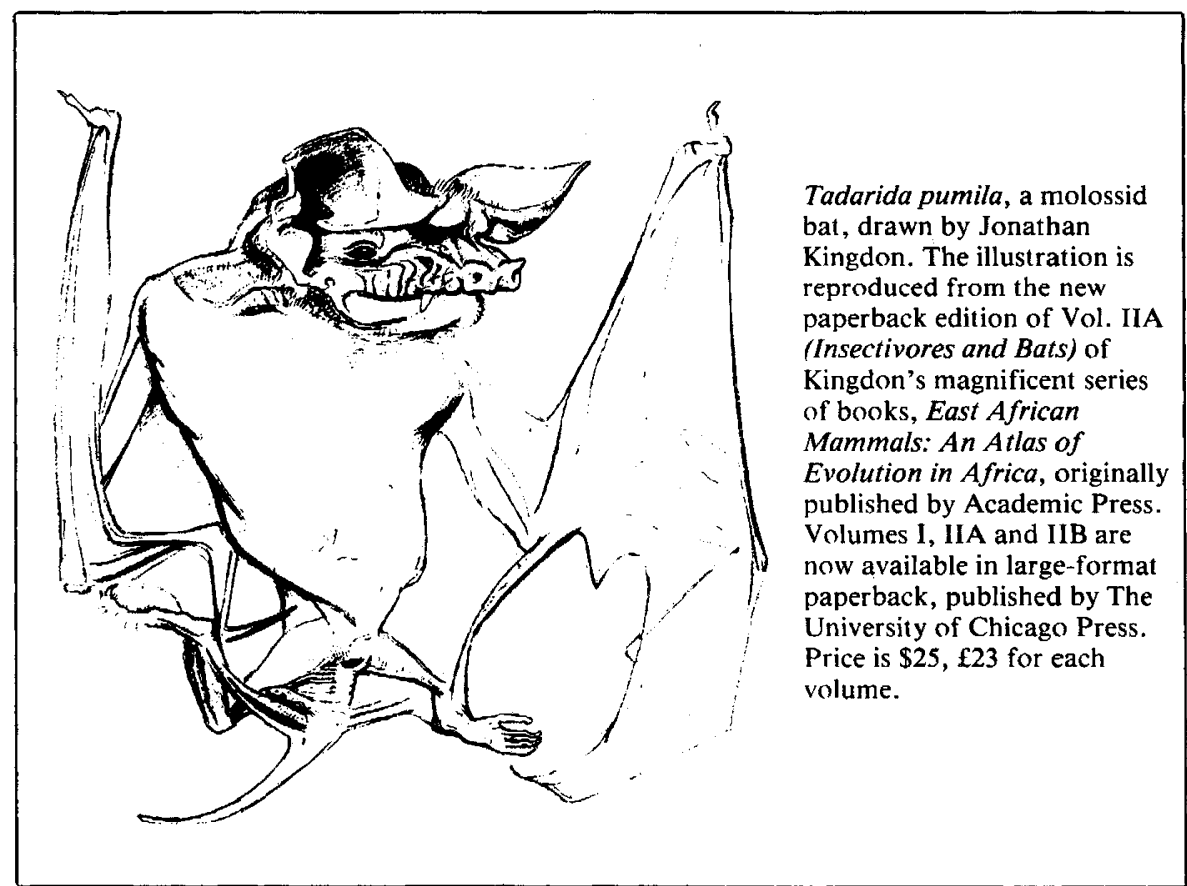

